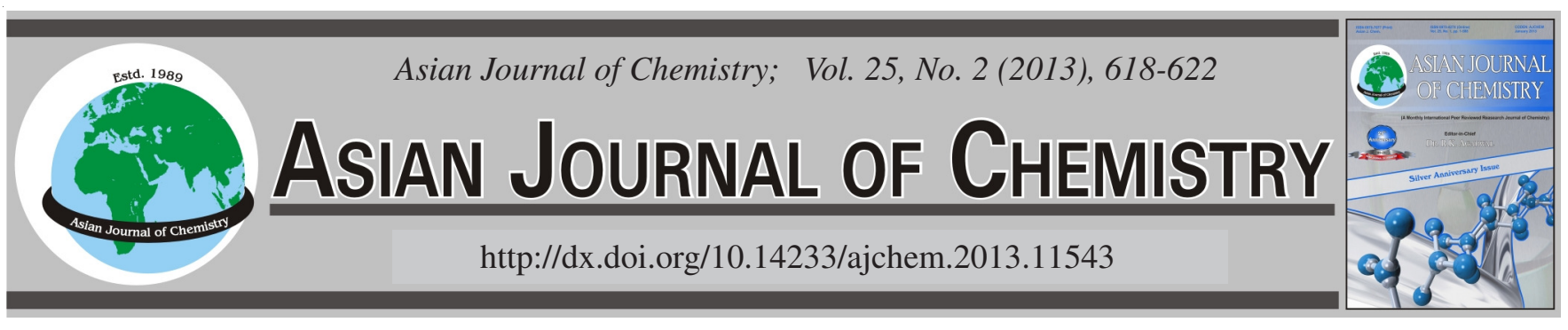

\title{
Effect on the Dewatering of Oily Scum Caused by Ultrasound
}

\author{
JiaAng Lu ${ }^{1,2}$, Ning Xu ${ }^{3}$, Yongunn Zhu ${ }^{3}$, Weili Jiang ${ }^{2}$, Pingfang Han ${ }^{4}$ and Xiaoping Lu ${ }^{1, *}$
}

${ }^{1}$ College of Chemistry and Chemical Engineering, Nanjing University of Technology, Nanjing, P.R. China

${ }^{2}$ Jiangsu Provincial Academy of Environmental Science, Nanjing, P.R. China

${ }^{3}$ College of Environment, Nanjing University of Technology, Nanjing, P.R. China

${ }^{4}$ College of Biotechnology and Pharmaceutical Engineering, Nanjing University of Technology, Nanjing, P.R. China

*Corresponding author: Fax: +86 25 83588072; Tel: +86 25 83712097; E-mail: xplu@ njut.edu.cn

(Received: 31 January 2011;

Accepted: 9 August 2012)

AJC-11941

\begin{abstract}
About 15000 tons of oily scum with poor usage for their high water-containing can be produced per year by Yangtze Petrochemical Co. Refinery. Experiment using ultrasound for pre-processing to reduce the water-containing, as well as reducing the volume of the oily scum was presented. Results from single factor experiments and orthogonal experiments gave the optimum values of some factors influencing dehydration efficiency such as frequency, voltage, ultrasonic treatment time and temperature, sedimentation temperature, etc. The importance of each factor was determined. Compared with the original technology, the ultrasound method is obviously superior in saving the depletion of flocculants to make the processing cost much lower for the same result and meantime in making the water-containing of the oily scum lower in the same condition of sedimentation. The dewatered oily scum could be used in the delayed coking process.
\end{abstract}

Key Words: Ultrasound, Oily scum, Dehydration.

\section{INTRODUCTION}

The oily scum usually comes from the wastewater treatment process in the refinery because of the amount use of aluminum inorganic flocculants. The water in oily scum is $c a$. $70-95 \%$ and exists in the form of freedom water. Oil content is ca. 4-30\% and the remaining solid compounds are $c a$. 5-7 $\%^{1}$. It is reported ${ }^{2}$ that the heat value of oily scum exceeds 16 $\mathrm{MJ} \mathrm{kg}^{-1}$ so that it must be recovered. The utilization of oily scum is limited because of its high water-containing. In order to recover the oily scum efficiently a dewatering pretreatment of oily scum is necessary.

At present, the main dewatering ways in production are filter-pressing and centrifugation, but the great investment is a bottleneck of restricting the developments of the abovementioned ways. On the other hand, the mud cake produced from previous ways is useless so it should be treated again in case of the second pollution to the environment.

Many results indicate that the technology of ultrasonic de-emulsification which shows low energy consumption and no pollution to the environment is an effective method to intensify de-emulsification and dehydration of any emulsion. It is indicated ${ }^{3-6}$ that the ultrasound can deemulsify almost every kind of emulsions which is achieved by the displacement effect of the ultrasound. Also the properties of treated medium may influence the efficiency of de-emulsification. The water droplets in the oily scum move towards the wave amplitude and wave node continuously, at the meantime the water droplets collide between themselves and gather into bigger particles. All above could accelerate the water particle's sedimentation velocity. At the same time, the physical or chemical functions including local thermal effect, voice efflux and cavitations caused by ultrasound can also influence the performance of dehydration. It is expressed in a patent ${ }^{7}$ that the watercontaining of the oily scum can be reduced after a few steps by ultrasound. First of all, the water-containing can be reduced by the elementary gravity sedimentations by themselves; secondly, adjust the $\mathrm{pH}$ value of the oily scum to 7.1 ; then add some flocculants for example polyacrylamide or polyaluminium chloride into the emulsion and mix the liquid to a homogeneous state; irradiate the mixture with ultrasound for several minutes. Finally sent the liquid to the second settling basin. After several hours for sedimentation, the watercontaining could be decreased from 93 to $c a .53 \%$. The mud cake caused by flocculants is useless although the watercontaining decreased remarkably. So the research emphases are on the dewatering ways without any flocculants.

This experiment researches the conditions for the dehydration of the oily scum from Yangtze Petrochemical Co. Refinery by ultrasound without flocculants and carries out the 
orthogonal experiments to determine the importance of every factor including the output electrical pressure, frequency of ultrasound, operation time, ultrasonic treatment temperature and sedimentation temperature etc. The optimum value of every factor can be determined by the analyses of the data using analysis of variance.

\section{EXPERIMENTAL}

The oily scum provided from Yangtze Petrochemical Co. Refinery and dimethyl benzene (AR) are used.

Analytical method: The water-containing of the oily scum is measured by Distillation (GB8939-88). The voltage of ultrasonic transducer can be read from the dial of ultrasound generator.

Steps: Experimental steps are as follows: at first, weigh $5 \mathrm{~g}$ of oily scum using analytical balance and measure the original water-containing of the oily scum using distillation; then irradiate the emulsion with the ultrasound produced by the ultrasonic generator for several minutes and then separate the water layer using separating funnel after $6 \mathrm{~h}$ sedimentation in the water bath with constant temperature; later, shake up the remaining oily scum and measure the water-containing again and finally compare the two water-containing values.

Setup: The instruments used are composed of ultrasonic generator, oscillograph, analytical balance, separating funnel, water-containing analytical equipment etc. The setting drawing is shown in Fig. 1.

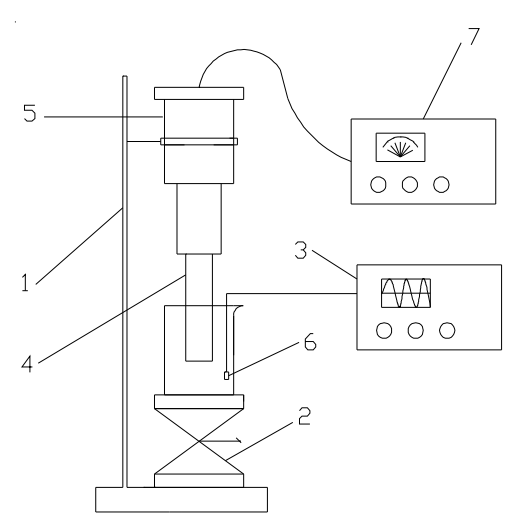

Fig. 1. Ultrasonic reactor. 1. Iron desk 2. Elevating table. 3. Oscillograph. 4. Probe. 5. Ultrasonic transducer. 6. Hydrophone. 7. Ultrasoic generator

\section{RESULTS AND DISCUSSION}

Comparison experiment: Because of the instability of the oily scum, the water-containing can reduce itself with the time's going by, inducing the decrease of its volume. According to a general treating method, the oily scum in the refinery was treated by settlement separation.

The experiment researched the sedimentation of the oily scum under two different conditions. First condition is the sedimentation with irradiation by ultrasound and the second is the direct sedimentation without ultrasound. The original water-containing of the oily scum was $85.7 \%$. Get the oily scum for $500 \mathrm{~mL}$ and divide it into two parts $(250 \mathrm{~mL}$ each). One part was irradiated with ultrasound; the other was without ultrasound then put them into two cylinders, respectively. The orifice of the cylinders was airproofed in case of the evaporation of the water in the oily scum. The sedimentation time 21 days and temperature $20^{\circ} \mathrm{C}$ were set.

After 21 day's settlement, separate the yielding water and then measure the final water-containing of the two parts of oily scum, respectively. The ultrasonic frequency was $10.4 \mathrm{kHz}$ and the output voltage was $80 \mathrm{~V}$, irradiate the oily scum for 5 min.

With ultrasound: The final water-containing of the oily scum could reduce to $68.2 \%$ and the volume decreased to $112 \mathrm{~mL}$ from the original volume of $250 \mathrm{~mL}$. It was ca. $44.8 \%$ of the original volume.

Without ultrasound: The final water-containing of the oily scum arrived to $c a$. $69.8 \%$ and the volume reduced to $118 \mathrm{~mL}$ from the original volume of $250 \mathrm{~mL}$. It was $c a .47 .2$ $\%$ of the original volume.

Fig. 2 indicates the results of the experiments. It showed clearly that the water-containing of the oily scum can reduce with the time's going by. The extent of the reduction becomes smaller and smaller with the sedimentation time, that is to say on the first few days the reduction is relatively faster. The watercontaining of oily scum with ultrasound can reduce to $72.9 \%$ after 2 day's sedimentation, while it cost 5 days to reach the same value without ultrasound. The adding of ultrasound can shorten the sedimentation time when reaches the same effect. Besides, the yield water with ultrasound is bigger than that without ultrasound, leading to a lower final water-containing.

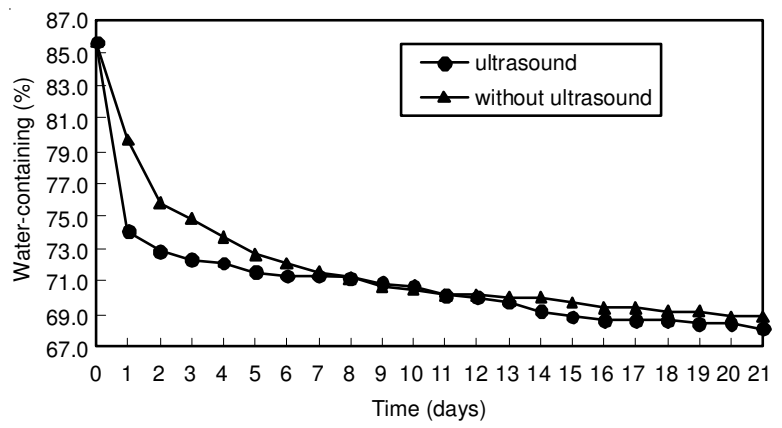

Fig. 2. Water-containing of oily scum by sedimentation

Single factor experiments: Single factor experiments were carried out to study the effects of every factor including the frequency and intensity of ultrasound, the treatment time, sedimentation time and sedimentation temperature.

Frequency of ultrasound: Experiment was carried under the condition: the intensity of ultrasound, $500 \mathrm{~W} \mathrm{~m}^{-2}$; the ultrasonic treatment time was $7 \mathrm{~min}$. The original watercontaining was $97.1 \%$.

It could be seen from Fig. 3 that low frequency had a better effect on the dehydration of the scum.

Intensity of ultrasound: Experiment was carried under the condition: the frequency of ultrasound, $20 \mathrm{kHz}$; the sedimentation time was $6 \mathrm{~h}$ and the sedimentation temperature was $70^{\circ} \mathrm{C}$. The original water-containing was $66.3 \%$.

It could be seen from Fig. 4 that the dehydration could reach a best effect when the intensity of ultrasound was 500 $\mathrm{W} \mathrm{m} \mathrm{m}^{-2}$.

Treatment time: Experiment was carried under the condition: the frequency of ultrasound, $20 \mathrm{kHz}$; intensity of 


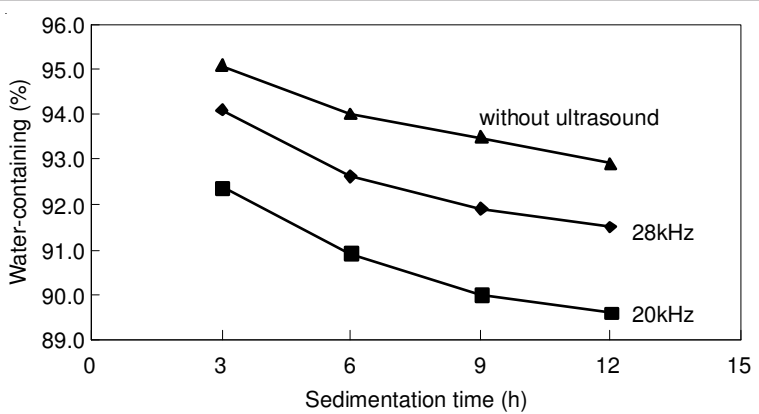

Fig. 3. Effect of dehydration caused by sedimentation time

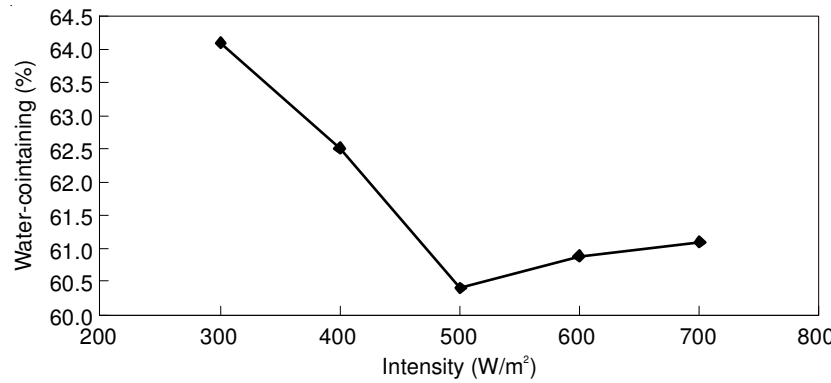

Fig. 4. Effect of dehydration caused by intensity of the ultrasound

ultrasound, $500 \mathrm{~W} \mathrm{~m}^{-2}$; the sedimentation time was $6 \mathrm{~h}$ and the sedimentation temperature was $70^{\circ} \mathrm{C}$. The original watercontaining was $65.2 \%$. The change was shown by Fig. 5. It could be seen that the dehydration could reach a best effect when the treatment time was $7 \mathrm{~min}$.

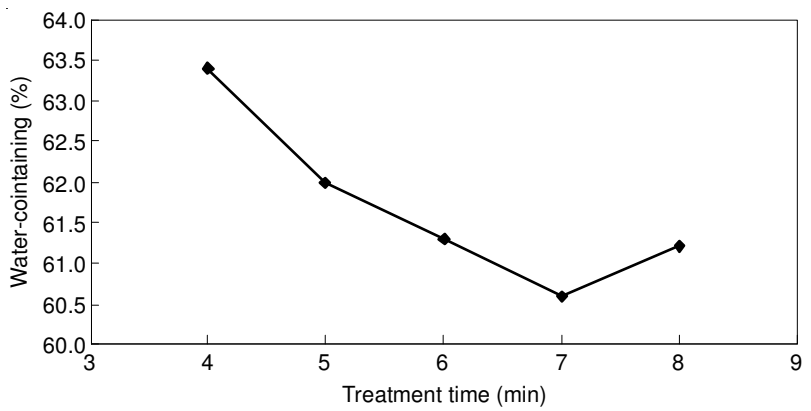

Fig. 5. Effect of dehydration caused by treatment time

Sedimentation time: Experiment was carried under the condition: the frequency of ultrasound, $20 \mathrm{kHz}$; intensity of ultrasound, $500 \mathrm{~W} \mathrm{~m}^{-2}$; the treatment time was $7 \mathrm{~min}$ and the sedimentation temperature was $70{ }^{\circ} \mathrm{C}$. The original watercontaining was $66.9 \%$. The change was shown by Fig. 6 . The water-containing can decrease with the sedimentation time and the extent also decreased.

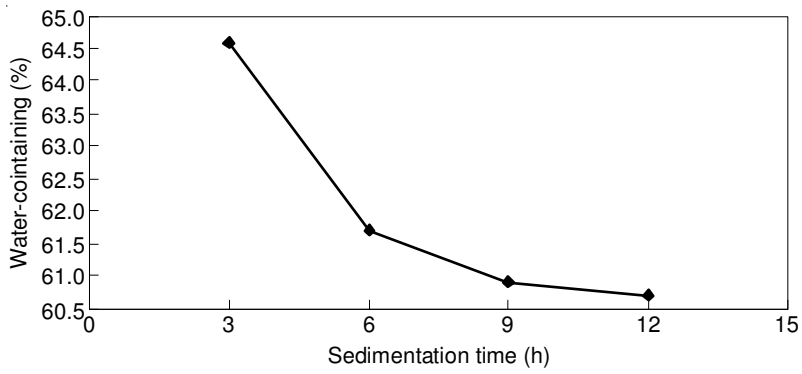

Fig. 6. Effect of dehydration caused by sedimentation time
Sedimentation temperature: Experiment was carried under the condition: the frequency of ultrasound, $20 \mathrm{kHz}$; intensity of ultrasound, $500 \mathrm{~W} \mathrm{~m}^{-2}$; the treatment time was $7 \mathrm{~min}$ and the sedimentation time was $6 \mathrm{~h}$. The original watercontaining was $63.1 \%$. The change was shown by Fig. 7 .

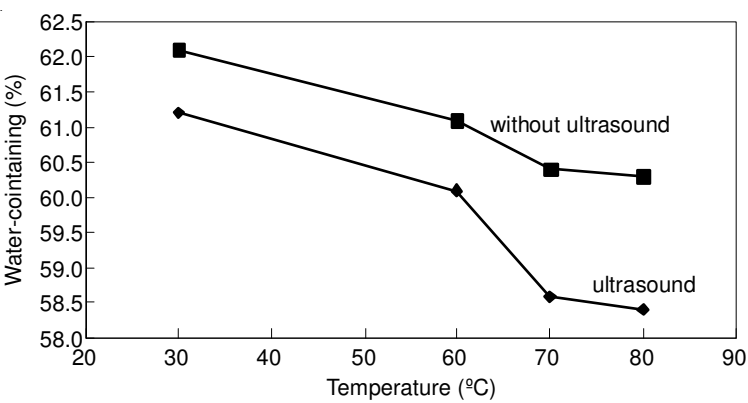

Fig. 7. Effect of dehydration caused by treatment temperature

It can be concluded that high temperature can improve the effect of dehydration more rapidly compared with the lower temperature.

Orthogonal experiments: Some operation parameters usually including the voltage, frequency of ultrasound, ultrasonic temperature, operation time and sedimentation temperature etc., should be optimized when the emulsion was irradiated with ultrasound. The voltage from the dial of ultrasound generator is the output electrical pressure of the ultrasonic generator. It is relevant to the ultrasonic intensity. When calculating the ultrasonic intensity, use the formula as follows:

$$
I=\frac{V^{2}}{2 M^{2} \rho c}{ }^{1}
$$

where I is the intensity of ultrasound, $\mathrm{V}$ is the voltage of the dial, $\mathrm{M}$ is the sensitivity of the hydrophone (usually $\mathrm{M}$ is 31.6), $\rho$ is the density of the oily scum and c represents the sound velocity transmitting in the oily scum.

Results of primary experiments by single-factor analysis showed that the appropriate parameters of ultrasound on dehydration were: frequency, $20 \mathrm{kHz}$; intensity, $500 \mathrm{~W} \mathrm{~m}^{-2}$; irradiation time, $7 \mathrm{~min}$ and the sedimentation time was $6 \mathrm{~h}$; the sedimentation temperature was $70^{\circ} \mathrm{C}$. According to the primary experiments, the longer the sedimentation time is, the lower the water-containing is. So in the orthogonal experiments, we set the sedimentation time for $6 \mathrm{~h}$. In order to study the repeatability of the experiments and the importance of each factor, an orthogonal experiment with five factors and four levels was designed. The experimental data was analyzed by variance analysis.

The dehydration efficiency $(\delta)$ is used as the evaluating indicator which is governed by the equation:

$$
\delta=\frac{\left(\eta_{1}-\eta_{2}\right)}{\eta_{1}} \times 100 \%
$$

where $\eta_{1}$ is the original water-containing of the oily scum, $\eta_{2}$ is the water-containing of the oily scum after the irradiation of ultrasound.

The formula for calculating the range is ruled by the equation: 


$$
\mathrm{R}=\frac{\left(\mathrm{K}_{\max }-\mathrm{K}_{\min }\right)}{4}
$$

where $\mathrm{K}_{\max }$ is the maximum of $\mathrm{K}$ value in every random array, $\mathrm{K}_{\text {min }}$ is the minimum of $\mathrm{K}$ value in every random array.

Data deduced from the orthogonal experiments were shown in Table-2. Table-2 indicates that most of the dehydration ratio of every group of oily scum could reach more than $10 \%$, which verified the function of the ultrasound for de-emulsification of the oily scum. The importance of each factor could be determined by the size of $\mathrm{R}$ value. After comparison we could see that the most important factor was ultrasonic frequency, next was sedimentation temperature. Voltage of the ultrasonic transducer, operation time and temperature were becoming less and less important. Table-2 suggests that each factor corresponded an optimal level. The data by orthogonal experiments were in accordance with that from primary experiments.

Experiment was carried under the condition: ultrasonic frequency, $10.4 \mathrm{kHz}$; output voltage of ultrasonic generator, $80 \mathrm{~V}$; the ultrasonic treatment time was $5 \mathrm{~min}$; ultrasonic temperature, $80{ }^{\circ} \mathrm{C}$ and the sedimentation temperature was $70{ }^{\circ} \mathrm{C}$. The water-containing could reduced from 88.0-72.3\%. The dehydration efficiency was $c a .17 .9 \%$, indicating that the data from orthogonal experiment had a good repeatability.

\section{Conclusion}

The main factors that can influence the dehydration efficiency include ultrasonic frequency, ultrasonic intensity, operation time, ultrasonic treatment temperature and sedimentation temperature etc. Orthogonal experiment results showed that the optimum values were: the frequency of ultrasound, $10.4 \mathrm{kHz}$; the output voltage of ultrasonic generator, $80 \mathrm{~V}$; the ultrasound treatment time was $5 \mathrm{~min}$; the ultrasonic temperature, $80^{\circ} \mathrm{C}$ and the sedimentation temperature was $70{ }^{\circ} \mathrm{C}$.

The differences between the data from primary experiment and orthogonal experiments were compared, finding that ultrasonic frequency and operation time were different mainly. The reason might be relevant to the original water-containing of the oily scum. The experiments were carried out at different groups of oily scum. The original water-containing of primary experiment and orthogonal experiment were 63.1 and $85.7 \%$. When the original water-containing of oily scum was low, the diameter of the water droplets was smaller than that of high original water-containing. Usually the quality of water drop is proportional to the size of the drop. According to the theory of natural frequency, the frequency of light particles is bigger. The condition of producing syntony between the water particles and sound wave is that the two frequencies should be near. So the frequency of the two experiments with different original water-containing is different. The small water droplets in the oily scum need enough time to coalesce into big drops, so the ultrasonic treatment time is longer than that of high original water-containing in certain ultrasonic power.

The improvement of dehydration performance by ultrasound can be illuminated from two aspects. First, the sound

\begin{tabular}{cccccc}
\multicolumn{7}{c}{ TABLE-1 } \\
\hline \multirow{2}{*}{ Level } & \multicolumn{5}{c}{ FACTORS AND LEVELS OF ORTHOGONAL EXPERIMENTS } \\
\cline { 2 - 6 } & $\begin{array}{c}\text { Foltage } \\
\text { (A) }(\mathrm{V})\end{array}$ & $\begin{array}{c}\text { Frequency } \\
(\mathrm{B})(\mathrm{kHz})\end{array}$ & $\begin{array}{c}\text { Ultrasonic temperature } \\
\text { (C) }\left({ }^{\circ} \mathrm{C}\right)\end{array}$ & $\begin{array}{c}\text { Operation time } \\
\text { (D) }(\min )\end{array}$ & $\begin{array}{c}\text { Sedimentation } \\
\text { temperature }(\mathrm{E})\left({ }^{\circ} \mathrm{C}\right)\end{array}$ \\
\hline 1 & 80 & 10.4 & 50 & 5 & 50 \\
2 & 120 & 20 & 60 & 7 & 60 \\
3 & 160 & 28 & 70 & 9 & 70 \\
4 & 200 & 40 & 80 & 11 & 80 \\
\hline
\end{tabular}

\begin{tabular}{|c|c|c|c|c|c|c|c|c|}
\hline \multicolumn{9}{|c|}{$\begin{array}{c}\text { TABLE-2 } \\
\text { RESULTS OF ORTHOGONAL EXPERIMENTS }\end{array}$} \\
\hline Serial number & $\mathrm{A}(\mathrm{V})$ & $\mathrm{B}(\mathrm{kHz})$ & $\mathrm{C}\left({ }^{\circ} \mathrm{C}\right)$ & $\mathrm{D}(\mathrm{min})$ & $\mathrm{E}\left({ }^{\circ} \mathrm{C}\right)$ & $\eta_{1}(\%)$ & $\eta_{2}(\%)$ & $\delta(\%)$ \\
\hline 1 & $\mathrm{~A}_{1}$ & $\mathrm{~B}_{1}$ & $\mathrm{C}_{1}$ & $\mathrm{D}_{1}$ & $E_{1}$ & 86.1 & 71.7 & 16.7 \\
\hline 2 & $\mathrm{~A}_{1}$ & $\mathrm{~B}_{2}$ & $\mathrm{C}_{2}$ & $\mathrm{D}_{2}$ & $\mathrm{E}_{2}$ & 85.0 & 75.8 & 10.8 \\
\hline 3 & $\mathrm{~A}_{1}$ & $\mathrm{~B}_{3}$ & $\mathrm{C}_{3}$ & $D_{3}$ & $\mathrm{E}_{3}$ & 88.2 & 74.2 & 15.9 \\
\hline 4 & $\mathrm{~A}_{1}$ & $\mathrm{~B}_{4}$ & $\mathrm{C}_{4}$ & $\mathrm{D}_{4}$ & $\mathrm{E}_{4}$ & 84.8 & 72.5 & 14.5 \\
\hline 5 & $\mathrm{~A}_{2}$ & $\mathrm{~B}_{1}$ & $\mathrm{C}_{2}$ & $\mathrm{D}_{3}$ & $\mathrm{E}_{4}$ & 88.5 & 73.0 & 17.5 \\
\hline 6 & $\mathrm{~A}_{2}$ & $\mathrm{~B}_{2}$ & $\mathrm{C}_{1}$ & $\mathrm{D}_{4}$ & $E_{3}$ & 86.2 & 74.8 & 13.2 \\
\hline 7 & $\mathrm{~A}_{2}$ & $\mathrm{~B}_{3}$ & $\mathrm{C}_{4}$ & $\mathrm{D}_{1}$ & $\mathrm{E}_{2}$ & 84.2 & 69.5 & 17.5 \\
\hline 8 & $\mathrm{~A}_{2}$ & $\mathrm{~B}_{4}$ & $\mathrm{C}_{3}$ & $D_{2}$ & $\mathrm{E}_{1}$ & 86.2 & 76.3 & 11.5 \\
\hline 9 & $\mathrm{~A}_{3}$ & $\mathrm{~B}_{1}$ & $\mathrm{C}_{3}$ & $\mathrm{D}_{4}$ & $\mathrm{E}_{2}$ & 88.3 & 79.0 & 10.5 \\
\hline 10 & $\mathrm{~A}_{3}$ & $\mathrm{~B}_{2}$ & $\mathrm{C}_{4}$ & $D_{3}$ & $E_{1}$ & 86.2 & 80.2 & 7.0 \\
\hline 11 & $\mathrm{~A}_{3}$ & $\mathrm{~B}_{3}$ & $\mathrm{C}_{1}$ & $\mathrm{D}_{2}$ & $\mathrm{E}_{4}$ & 85.4 & 75.2 & 11.9 \\
\hline 12 & $\mathrm{~A}_{3}$ & $\mathrm{~B}_{4}$ & $\mathrm{C}_{2}$ & $\mathrm{D}_{1}$ & $\mathrm{E}_{3}$ & 86.2 & 71.9 & 16.6 \\
\hline 13 & $\mathrm{~A}_{4}$ & $\mathrm{~B}_{1}$ & $\mathrm{C}_{4}$ & $D_{2}$ & $\mathrm{E}_{3}$ & 86.2 & 71.5 & 17.1 \\
\hline 14 & $\mathrm{~A}_{4}$ & $\mathrm{~B}_{2}$ & $\mathrm{C}_{3}$ & $\mathrm{D}_{1}$ & $\mathrm{E}_{4}$ & 86.2 & 74.8 & 13.2 \\
\hline 15 & $\mathrm{~A}_{4}$ & $\mathrm{~B}_{3}$ & $\mathrm{C}_{2}$ & $\mathrm{D}_{4}$ & $E_{1}$ & 85.5 & 73.1 & 14.5 \\
\hline 16 & $\mathrm{~A}_{4}$ & $\mathrm{~B}_{4}$ & $\mathrm{C}_{1}$ & $D_{3}$ & $\mathrm{E}_{2}$ & 86.2 & 77.5 & 10.1 \\
\hline $\mathrm{K}_{1}$ & 59.7 & 61.8 & 51.9 & 64.0 & 49.7 & - & - & - \\
\hline $\mathrm{K}_{2}$ & 57.9 & 44.2 & 56.1 & 51.3 & 48.9 & - & - & - \\
\hline $\mathrm{K}_{3}$ & 46.0 & 59.8 & 51.1 & 50.5 & 62.8 & - & - & - \\
\hline $\mathrm{K}_{4}$ & 54.9 & 52.7 & 59.4 & 52.7 & 57.1 & - & - & - \\
\hline Range & 3.425 & 4.4 & 2.1 & 3.375 & 3.475 & - & - & - \\
\hline
\end{tabular}


energy can destroy the agglomerate of the oily scum, then its inside water is released; secondly, the thermal effect produced by the ultrasound can reduce the viscidity of the oily scum, which facilitates the sedimentation of the freedom water according to Stokes Gravity Sedimentation Theory.

The ultrasonic irradiation can improve the performance of dehydration when treating the oily scum, compared with original dehydration treatment. It can reduce the cost of treatments as a result of not using the flocculants and also shorten the treatment time. In addition, the combination of oily scum dewatering by ultrasonic and delayed coking process can recover the waste oil and solve the environmental problem.

The physical or chemical properties of oily scum may be dissimilar with different original water-containings, so the optimum value of the factors provided by the experiments may vary. But the tendence of primary and secondary factors may be accordant in different experimental study.

\section{ACKNOWLEDGEMENTS}

The authors thanks the University Natural Science Fund of Jiangsu Province, China (06KJB530041) and Yangtze Petrochemical Co.

\section{REFERENCES}

1. Y.F. Zhou, M.S. Thesis, Study on the Flocculation and Dehydration of Oily Scum in Petroleum Refinery Intensified by Ultrasound, Nanjing: Nanjing University of Technology, College of Chemical Technology (2005).

2. G.X. Ye, X.P. Lu, C.H. Shu, P.F. Han and Y.J. Zhu, Chem. Ind. Eng. Prog., 25, 1381 (2006).

3. G.K. Qin, Petroleum Geol. Recov. Efficiency, 12, 76 (2005).

4. B.J. Sun, D.C. Yan and W.X. Qiao, Acta Acustica, 24, 327 (1999).

5. H.K. Tsao and D.L. Koch, Fluids, 6, 2591 (1994).

6. E. Riera-Franco de Sarabia, J.A. Gallego-Juarez, G. Rodriguez-Corral, L. Elvira-Segura and I. Gonzalez-Gomez, Ultrasonics, 38, 642 (2000).

7. M.V. Krishna, J.R. Babu, P.V.M. Latha and D.G. Sankar, Asian J. Chem., 19, 1369 (2007). 